\title{
Uncertainty Analysis of a Fractured Reservoir's Performance: A Case Study
}

\author{
M. Khosravi ${ }^{1}$, B. Rostami ${ }^{2,3}$ and S. Fatemi ${ }^{3}$ \\ 1 Research Institute of EOR (NIOC), Tehran - Iran \\ 2 Chemical Engineering Department, College of Engineering, University of Tehran, Tehran - Iran \\ 3 Institute of Petroleum Engineering, University of Tehran, Tehran - Iran \\ e-mail: khosravi@nioc.rtd.ir - brostami@ut.ac.ir-shfatemi@ut.ac.ir
}

Résumé - Analyse d'incertitudes des performances d'un réservoir fracturé : étude de cas - Ces dernières années, l'industrie du pétrole a accordé une grande importance à la gestion et à l'analyse d'incertitudes des réservoirs. Le développement d'une méthode permettant de modéliser et de quantifier les incertitudes au cours des études de simulation de réservoir d'une façon efficace et pratique est clairement souhaitable. Des approches différentes telles que la méthodologie des surfaces de réponse (RSM ; Response Surface Methodology) et la simulation de Monte-Carlo ont été utilisées pour évaluer les incertitudes.

Au sein de cet article, la méthode de surface de réponse est utilisée pour appréhender les paramètres les plus influents sur les changements en termes de chute de pression et de facteur de récupération, en ce qui concerne leurs niveaux pratiques d'incertitudes au cours du développement d'un modèle de réservoir fracturé. La présente approche est utilisée pour amplifier les paramètres significatifs et développer une équation substitutive compatible et plus réaliste en vue de la prévision de la récupération d'huile à partir d'un réservoir fracturé faiblement perméable typique. Le modèle substitutif permet à l'analyse de MonteCarlo de déterminer les sensibilités et la quantification de l'incidence de l'incertitude sur les prévisions de production.

Les résultats indiquent que la récupération d'huile est plus sensible à la pression de l'aquifère, à la perméabilité de fracture et à la hauteur de bloc. De plus, toutefois, l'interaction entre d'autres paramètres tels que la taille de matrice, la perméabilité de fracture et le volume d'aquifère a montré un certain degré d'importance au cours de cette analyse. L'analyse de Monte-Carlo prévoit un domaine de grande ampleur de récupération d'huile pour l'exploitation de ce champ.

\begin{abstract}
Uncertainty Analysis of a Fractured Reservoir's Performances: A Case Study - In recent years, the oil industry has given great importance to reservoir management and reservoir uncertainty analysis. The development of a method that can model and quantify uncertainties in reservoir simulation studies in an efficient and practical way is clearly desirable. Different approaches such as Response Surface Methodology (RSM) and Monte-Carlo simulation have been used to address the uncertainties.

In this paper, response surface method is used to realize the most influential parameters on pressure drop and recovery factor changes, regarding their practical levels of uncertainties during the development of fractured reservoir model. The present approach is performed to magnify the significant parameters and developing compatible and more realistic proxy equation for forecasting oil recovery from a typical low permeable fractured reservoir. The proxy model allows Monte-Carlo analysis to determine sensitivities and the quantification of the impact of uncertainty on production forecasts.

Results indicate that the oil recovery is more sensitive to aquifer strength, fracture permeability and block height. In addition, however the interaction between other parameters, such as matrix size, fracture permeability and aquifer volume, showed a degree of importance during this analysis. Monte-Carlo analysis forecasts wide range of oil recovery for this field development.
\end{abstract}




\section{INTRODUCTION}

However, evaluation of petroleum field has become a much more accurate process because of high technology; many Iranian fractured carbonate reservoirs are characterized by significant and wide range of uncertainties, due to their high level of sub-surface heterogeneities. All these uncertainties finally lead to a complex reservoir model; therefore extension of the model (pressure and recovery factor of the field after a certain period of time) to a wide range of time produces unacceptable results. To reduce these uncertainties, petroleum industries require a framework consisting of evaluating sensitivities and estimating impact of uncertainties on the field performance $[1,2,12]$.

Experimental design, specially response surface methods and Monte-Carlo analysis, provide such a framework by arranging simulation models to maximize the information gained from each simulation, and to evaluate statistically the significance of different factors [11].

In last decades, petroleum industry has widely used experimental design methods to reduce different kinds of uncertainties during field developments. Peng and Gupta have gathered a data bank of the similar projects till 2004 [3]. This is especially important in financial evaluation of the projects. However, it is necessary to look at the full distribution of Net Present Value (NPV) for an individual asset, not just its expected value. Recent economic theory in Decision and Risk Analysis require more information than an average or expected NPV [4].

In this paper, uncertainties relating to one of Iranian fractured reservoir has been investigated and quantified. These uncertainties mostly come from unknown fracture network, aquifer volume and oil relative permeability. After illustrating the practical ranges of uncertainties for each reservoir parameter, mentioned above, it could be possible to define these ranges in three levels, means: low, base and high. Using reservoir simulation a 3D model could be designed using base values of uncertain parameters. Then RSM provides a suitable selection of 3D simulations, corresponding to known three level patterns. This leads to realize the effective parameters with most powerful effect on the responses; recovery and pressure, in addition, to develop proxy equations for the responses, which are then used to constrain the range of uncertainty in the response by Monte-Carlo simulations.

\section{Sources of Uncertainties in Reservoir Engineering}

Sources of uncertainties in this field are almost infinite and are anywhere within the reservoir modeling workflow, and could be classified as follows, as illustrated in Figure 1:

- static model (outcrops and regional studies, well log analysis and seismic acquisition);

- up-scaling (coarsening for highly heterogeneous and/or de-structured media);

- fluid flow modeling (relative permeability curves, well productivity, PVT or the solver);

- production data integration (measured well-production data);

- production scheme development and economic evaluation (optimization of the number of production wells, their location and architecture, injection schemes as well as some surface facilities) [1].

\section{Classification of Uncertainties}

As described above, reservoir evaluation and optimization require handling a very complex modeling on which many

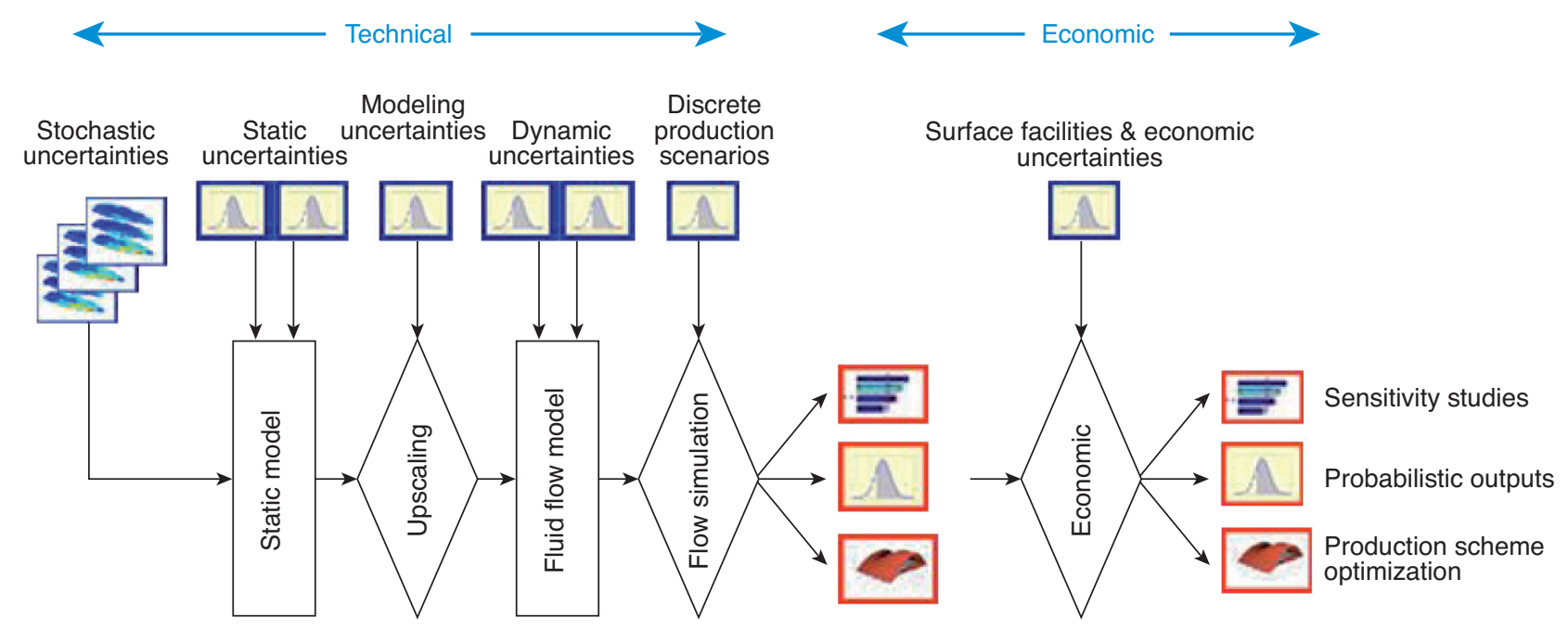

Figure 1

Sources of uncertainties in reservoir modeling workflow [1]. 
uncertainties remain. It is therefore very important to apply the right methodology to face each uncertainty in order to take the right decision in a risk-prone environment. Three different statistical behaviors can be used to classify the uncertainties:

- deterministic (continues parameters such as: mean facies permeability, porosity, matrix block size, etc.);

- discrete (depositional scenarios or fault conductivity, aquifer size, etc.);

- stochastic (infinity of equiprobable structural maps, fracture maps, geostatistical realizations, history matched models, etc.) [1].

\section{RESERVOIR MODEL AND UNCERTAINTY DESCRIPTION}

In reservoir engineering, it is necessary to handle any kind of uncertainties (deterministic, discrete, stochastic, etc.) while keeping the consistency of the modeling workflow.

In this study, it is desired to quantify the uncertainties in oil recovery factor and reservoir pressure drop after a certain period of production time (30 years); therefore, for the first step, it is necessary to find the most influential factors. In next step, the amount of their effect should be quantified via a proxy equation. It is possible to do some sensitive analysis, but it could just identify the uncertainties due to main effects, not the ones which come from interactions of different factors. Therefore, using experimental design analysis are the best methodology for this purpose, and then Monte-Carlo analysis should be used to evaluate the impact of uncertainty on production forecasts. The procedure has been schematized in Figure 2.
The studied field in this work is one of Iranian oil fields located in south part of Zagros. Static model of this field (including the grids, permeability and porosity maps, location of faults and wells) was prepared previously, But in order to construct a dynamic model it is necessary to convert the grid network to a fractured one (means matrix block size and fracture permeability should be known) and then it is crucial to assume a suitable set of relative permeability curves and a proper aquifer volume connected to the reservoir. To do this, commercial compositional modeling software is used (Fig. 3). Detail of the reservoir description is as followed.

\section{Reservoir Geology and Structure}

The field has $29 \times 10^{6}$ square meters of structural closure within the Water/Oil Contact (WOC) at $2464 \mathrm{~m}$ tvdss, giving a maximum field gross oil column of $432 \mathrm{~m}$. The structure of the field is shown in Figure 4. The field anticline is an onshore structure, lying immediately to the east of a big fault. Seismic profiles indicate a high relief anticlinal structure plunging to the northwest and southeast. The four-way dip closure is about 12488 by 6437 meters, at Asmari level which is the main producing reservoir in the studied field.

The productive zone of the field consists of 16 layers and average matrix porosity is around 7\%. Gross thickness is $432 \mathrm{~m}$ with average Net To Gross (NTG) of nearly 0.8. Permeability values measured on core plugs were used to determine the matrix permeability. Lower parts of Asmari formation contain mostly water with limited oil saturation that are acting as an aquifer; these layers were assumed as an analytical aquifer in the model as it takes less run time and easier analyses. Therefore, the analytical aquifer properties were chosen in a way to describe the numerical aquifer behavior precisely.

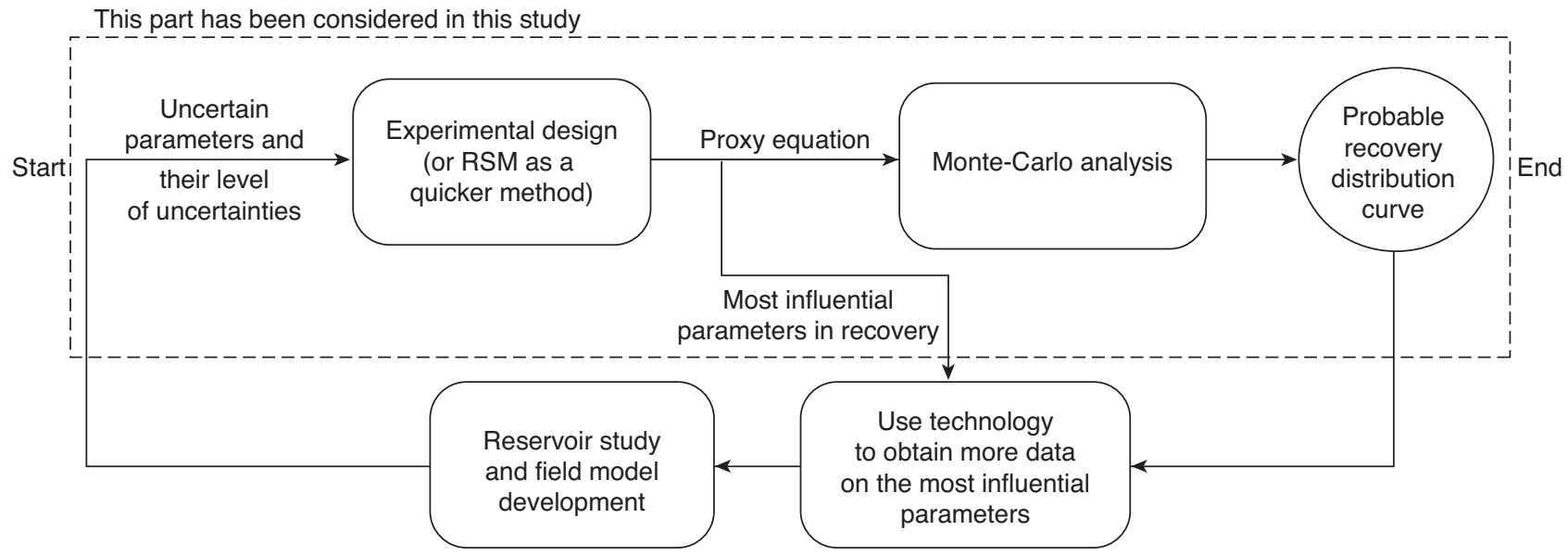

Figure 2

Schematic of the study procedure for analyzing reservoir uncertainties. 


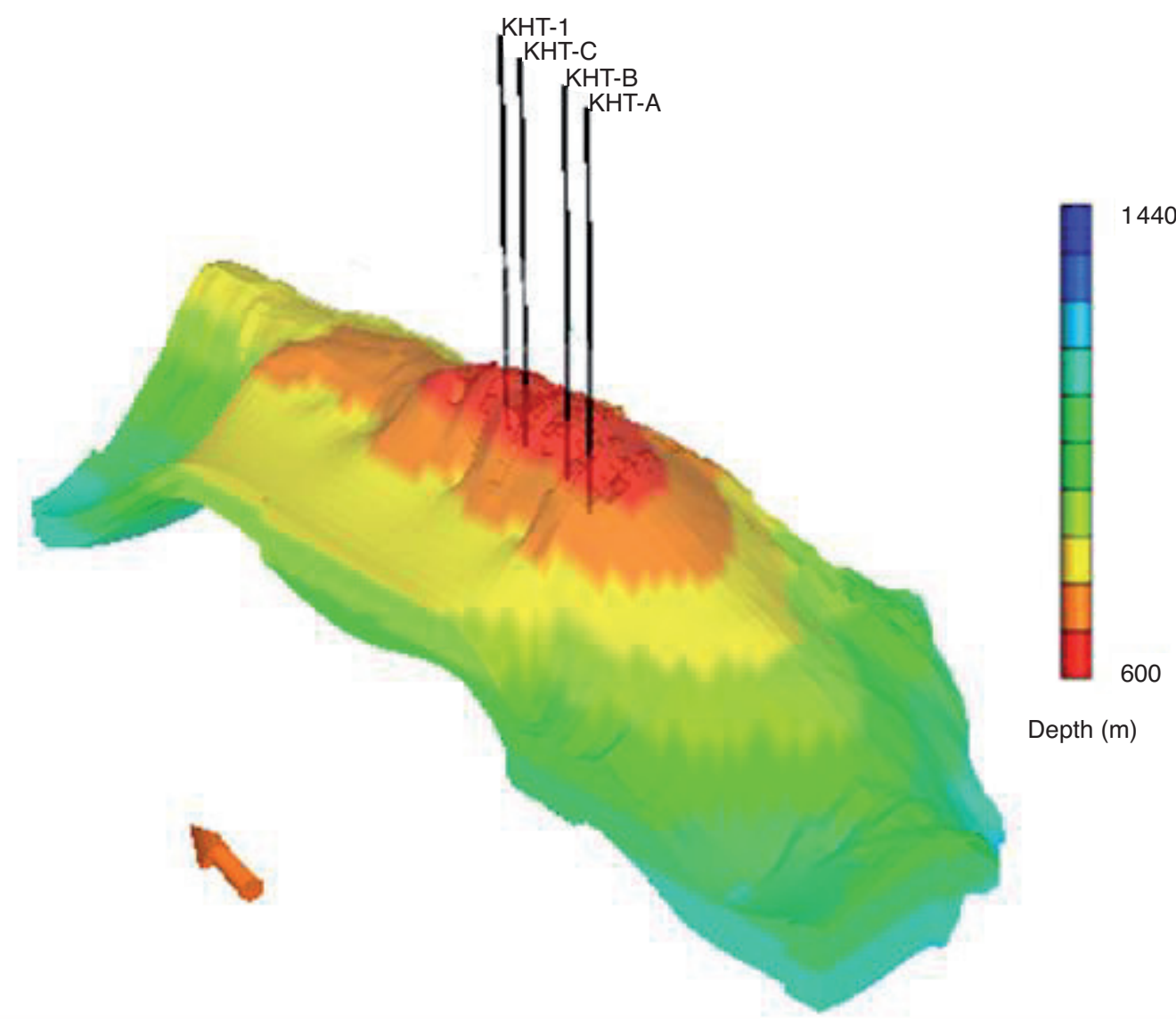

Figure 3

Schematic of the field modeled in compositional simulation software.

The best wells locations were determined by considering field structure and reservoir properties. Figure 3 also shows the location of 4 wells that were proposed in Master Development Plan (MDP) for initial production strategy.

\section{Fluid Properties and Equation of State}

The available Pressure/Volume/Temperature (PVT) data indicate the presence of oil with average $36^{\circ} \mathrm{API}$ and viscosity $5.72 \mathrm{cp}$. At initial reservoir conditions $\left(29.8 \mathrm{MPa}\right.$ and $\left.94^{\circ} \mathrm{C}\right)$, average Gas Oil Ratio (GOR) and oil formation volume factor vary between 71 to $125 \mathrm{std} . \mathrm{m}^{3} / \mathrm{m}^{3}$ and 1.1 to $1.5 \mathrm{res} . \mathrm{m}^{3} / \mathrm{std} . \mathrm{m}^{3}$ in that order, and bubble point pressure is $12.9 \mathrm{MPa}$. The salinity and viscosity of formation water are 160000 and 0.50 respectively. Compositional analyses of reservoir fluid indicate that it mostly consists of $24 \% \mathrm{C} 1$ and $46 \%$ of C7 + fractions.

The irreducible water and gas saturation and residual oil saturation with respect to water and gas were set as follows by using available data: $S_{w r}=0.15, S_{g r}=0.01, S_{\text {orw }}=0.25$, $S_{\text {org }}=0.3$.
The solution GOR at the saturation pressure and reservoir temperature is about $106.8 \mathrm{~m}^{3} / \mathrm{m}^{3}$. The cubic Peng-Robinson EOS model was tuned by adjusting the critical temperature, critical pressure, acentric factor, volume shift and binary interaction parameters of non-hydrocarbons to match all PVT data and laboratory tests. The critical pressure and temperature of oil are about $10.3 \mathrm{MPa}$ and $399^{\circ} \mathrm{C}$.

According to the field MDP a production scheme for 30 years with a plateau rate of $4769.6 \mathrm{~m}^{3} / \mathrm{D}$ and recovery factor of $22 \%$ (where the aquifer volume is equal to the oil volume) were considered as the base case development scheme (Fig. 4).

Primary Sensitivity analysis, using simulation results, show that six factors listed in Table 1 have the most important effect on production, while they have different levels of uncertainties. The upper and lower limits for the selected parameters are chosen based on vicinity fractured oil reservoirs located on the same fields. 


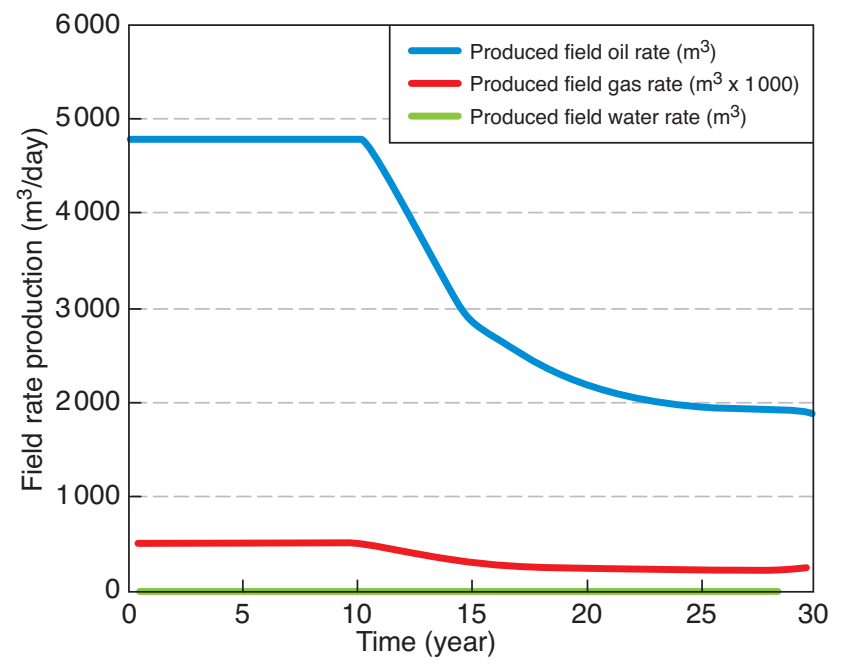

Figure 4

Base case production performance.

TABLE 1

Uncertainty levels of the most effective parameters

\begin{tabular}{|c|c|c|c|c|}
\hline & & Low & Base & High \\
\hline A & Matrix block size (m) & 1.52 & 3.05 & 4.57 \\
\hline $\mathrm{B}$ & Effective fracture permeability (md) ${ }^{1}$ & 10 & 23 & 36 \\
\hline $\mathrm{C}$ & $\begin{array}{l}\text { Vertical matrix permeability/Horizontal } \\
\text { matrix permeability }\end{array}$ & 0.1 & 0.2 & 0.3 \\
\hline $\mathrm{D}$ & Aquifer size/IOIP² & 0 & 1 & 2 \\
\hline E & Water relative permeability & 0.25 & 0.375 & 0.5 \\
\hline $\mathrm{F}$ & Oil relative permeability & 0.168 & 0.284 & 0.4 \\
\hline
\end{tabular}

${ }^{1}$ Fracture permeability times its porosity.

${ }^{2}$ Initial Oil In Place.

\section{EXPERIMENTAL DESIGN AND RESPONSE SURFACE METHODOLOGY}

Design Of Experiment (DOE) is used to generate response surfaces that identify the various factors that cause changes in the responses and also predict these variations in a simple mathematical form. The purpose of Response Surface Methodology (RSM) is to approximate a process over a region of interest. Engineers define objectives of the process called responses as the output and the settings for the state parameters and decision variables as input. RSM provides tools for:

- identifying the variables that influence the responses (screening) and;

- building regression models relating the responses to the strategic variables (modeling).

The final models are used to make predictions of the process over the domain [2].
Design of experiments is the application of statistical methods to determine the number and level of the variables in order to get most information at the lowest experimental runs. More details can be found in a related literature [5].

Experimental design methods were first studied in the oil/gas industry back in 1960s and 1970s, but were mainly applied in physical experiments. Most of the studies focus on the production performance (e.g. ultimate recovery) as the output response.

To select efficient designs for subsurface reservoir uncertainty studies, many design matrices ranging from 2 to $\leq 16$ variables with more than 3 levels, and up to $100 \mathrm{~s}$ of design runs have been studied, and they include: PlacketBurman, 2k-p fractional factorial designs, 3k-p fractional factorial designs, $2 \mathrm{k}$ and/or $3 \mathrm{k}$ full factorial, Central Composite, Box-Behnken, mixed 2- and 3-level full factorial, D-optimal, and other modified designs [3].

Expert opinion and knowledge about the experiments are very important to have a good understanding about independent effects and aliased one due to the limited degree of freedom in the design runs and therefore this could help to selection of a good method. Narayanan et al. (1999) [6], Chewaroungroaj et al. (2000) [7], White et al. (2001) [8], Risso et al. (2007) [9] and Rai et al. (2009) [10] have chosen Box-Behnken method to investigate the ultimate oil recovery of the field.

In this study, oil recovery factor and pressure decline are considered as response, and decision variables are presented in Table 1. Box-Behnken is chosen as the method of DOE, because primary investigations showed that factorial design could not provide any extra information in comparison with Box-Behnken, which reduces the number of experiments beneficially (note that this design would consist of $3^{6}=729$ if the method of full factorial was performed), see Table 2.

Box-Behnken experimental designs for Response Surface Methodology, devised by George E. P. Box and Donald Behnken in 1960 (Fig. 5), could be introduced simply as a design which begins from three factors, is a three level design, can predict the quadratic effect of each factor with less experiments than Central Composite Design (CCD), and would not use the corner points.

Table 2 shows Box-Behnken design for six factors, first column is the standard order of the experiments, next columns show the rotation of levels for different factors introduced in Table 1 and overall 49 experiments is suggested for the whole analysis.

\section{RESULTS AND DISCUSSION}

Corresponding to the pattern introduced in Table 2, 49 different 3D reservoir models have been prepared and each full field reservoir model run took approximately eigth hours to be completed. The percentage of oil recovery (\%) and reservoir 


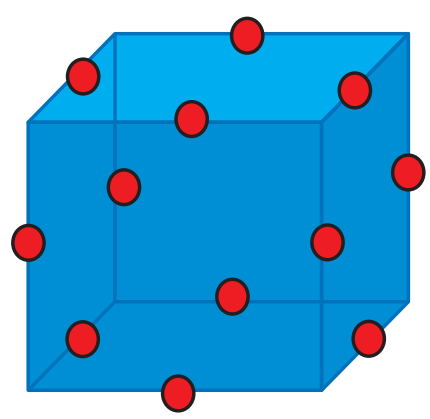

Figure 5

A Box-Behnken design for three factors.

TABLE 2

Box-Behnken design for six uncertain variables

\begin{tabular}{|c|c|c|c|c|c|c|c|c|c|c|c|c|c|}
\hline Run & $A$ & $B$ & $C$ & $D$ & $E$ & $F$ & Run & $A$ & $B$ & $C$ & $D$ & $E$ & $F$ \\
\hline 1 & - & - & 0 & - & 0 & 0 & 26 & + & 0 & 0 & - & - & 0 \\
\hline 2 & + & - & 0 & - & 0 & 0 & 27 & - & 0 & 0 & + & - & 0 \\
\hline 3 & - & + & 0 & - & 0 & 0 & 28 & + & 0 & 0 & + & - & 0 \\
\hline 4 & + & + & 0 & - & 0 & 0 & 29 & - & 0 & 0 & - & + & 0 \\
\hline 5 & - & - & 0 & + & 0 & 0 & 30 & + & 0 & 0 & - & + & 0 \\
\hline 6 & + & - & 0 & + & 0 & 0 & 31 & - & 0 & 0 & + & + & 0 \\
\hline 7 & - & + & 0 & + & 0 & 0 & 32 & + & 0 & 0 & + & + & 0 \\
\hline 8 & + & + & 0 & + & 0 & 0 & 33 & 0 & - & 0 & 0 & - & - \\
\hline 9 & 0 & - & - & 0 & - & 0 & 34 & 0 & + & 0 & 0 & - & - \\
\hline 10 & 0 & + & - & 0 & - & 0 & 35 & 0 & - & 0 & 0 & + & - \\
\hline 11 & 0 & - & + & 0 & - & 0 & 36 & 0 & + & 0 & 0 & + & - \\
\hline 12 & 0 & + & + & 0 & - & 0 & 37 & 0 & - & 0 & 0 & - & + \\
\hline 13 & 0 & - & - & 0 & + & 0 & 38 & 0 & + & 0 & 0 & - & + \\
\hline 14 & 0 & + & - & 0 & + & 0 & 39 & 0 & - & 0 & 0 & + & + \\
\hline 15 & 0 & - & + & 0 & + & 0 & 40 & 0 & + & 0 & 0 & + & + \\
\hline 16 & 0 & + & + & 0 & + & 0 & 41 & - & 0 & - & 0 & 0 & - \\
\hline 17 & 0 & 0 & - & - & 0 & - & 42 & + & 0 & - & 0 & 0 & - \\
\hline 18 & 0 & 0 & + & - & 0 & - & 43 & - & 0 & + & 0 & 0 & - \\
\hline 19 & 0 & 0 & - & + & 0 & - & 44 & + & 0 & + & 0 & 0 & - \\
\hline 20 & 0 & 0 & + & + & 0 & - & 45 & - & 0 & - & 0 & 0 & + \\
\hline 21 & 0 & 0 & - & - & 0 & + & 46 & + & 0 & - & 0 & 0 & + \\
\hline 22 & 0 & 0 & + & - & 0 & + & 47 & - & 0 & + & 0 & 0 & + \\
\hline 23 & 0 & 0 & - & + & 0 & + & 48 & + & 0 & + & 0 & 0 & + \\
\hline 24 & 0 & 0 & + & + & 0 & + & 49 & 0 & 0 & 0 & 0 & 0 & 0 \\
\hline 25 & - & 0 & 0 & - & - & 0 & & & & & & & \\
\hline
\end{tabular}

pressure (MPa), at the end of 30 years of natuural depletion, are reported in Table 3.

During Analysis of Variance (ANOVA), the confidence level was considered as $5 \%$ while $R$-square was calculated as 0.9926 and adjusted one as 0.9830 , it could be saying that analysis was reliable. For the next step, after elimination of insignificat terms, following equation was obtained in terms of uncoded values:

$$
\begin{aligned}
\% \text { Recovery }= & +18.24206 \\
& -0.225732 \times \text { Matrix size } \\
& +0.33553 \times \text { Fracture perm. } \\
& +7.02156 \times \text { Aquifer vol./IOIP } \\
& +1.90374 \times K_{r o} \\
& -1.73502 \mathrm{E}-03 \times \text { Matrix size } \times \text { Fracture perm. } \\
& -0.029375 \times \text { Matrix size } \times \text { Aquifer vol./IOIP } \\
& +0.074038 \times \text { Fracture perm. } \times \text { Aquifer vol./IOIP } \\
& +0.0929 \times \text { Matrix size }^{2} \\
& -5.05672 \mathrm{E}-03 \times \text { Fracture perm. }^{2} \\
& -1.85264 \times \text { Aquifer vol./IOIP }
\end{aligned}
$$

Results of analysis of variance showed that " $K_{v} / K_{h}$ " (Vertical Permeability/Horizontal Permeability) and " $K_{r w}$ " (Water Relative Permeability) had no significant effect on oil recovery within the proposed range of variations; while the ratio of aquifer volume to IOIP, matrix block size and fracture permeability had important effects. Oil recovery was a week function of oil relative permeability while the reservoir was fractured, because, oil relative permeability was included only in fluid flow equations of matrix, and the whole calculated flux from matrix was considered as a source or sink for fractures fluid flow equations.

Figure 6 shows the dependency of the oil recovery to factors $A, B, F$ and $D$, within a normalized range of investigation. Zero point is corresponding to the base case properties as shown in this figure.

With the same procedure a mathematical relation could be derived for field's pressure variation:

Pressure $(\mathrm{MPa})=$

$+19.0885$

$-0.0106454 \times$ Matrix size

$-0.228004 \times$ Fracture perm.

$+1.86572 \times$ Aquifer vol./IOIP

$-0.0309448 \times$ Fracture perm. $\times$ Aquifer vol./IOIP

$+0.00382583 \times$ Fracture perm. $^{2}$

$-0.198757 \times$ Aquifer vol./IOIP ${ }^{2}$

Finally, these equations were used in Monte-Carlo simulation technique for further analysis, and to find the range of response uncertainty due to uncertainties exist in main factors and their interactions can be computed in Monte-Carlo analysis.

While no enough information was available for possible distribution of the variables; main factors are introduced with uniform probability functions which have the same extremisms 
TABLE 3

Results of compositional simulation used in DOE as response

\begin{tabular}{|c|c|c|c|c|c|c|c|c|}
\hline Run & Matrix size (m) & Fracture perm. (md) & $K_{v} / K_{x}$ & Aquifer vol./IOIP & $K_{r w}$ & $K_{r o}$ & Recovery (\%) & Pressure $(\mathrm{MPa})$ \\
\hline 1 & 1.52 & 10 & 0.2 & 0 & 0.375 & 0.3 & 18 & 16.7 \\
\hline 2 & 4.57 & 10 & 0.2 & 0 & 0.375 & 0.3 & 16 & 16.3 \\
\hline 3 & 1.52 & 36 & 0.2 & 0 & 0.375 & 0.3 & 20 & 15.5 \\
\hline 4 & 4.57 & 36 & 0.2 & 0 & 0.375 & 0.3 & 17 & 15.4 \\
\hline 5 & 1.52 & 10 & 0.2 & 2 & 0.375 & 0.3 & 25 & 19.4 \\
\hline 6 & 4.57 & 10 & 0.2 & 2 & 0.375 & 0.3 & 21 & 18.8 \\
\hline 7 & 1.52 & 36 & 0.2 & 2 & 0.375 & 0.3 & 31 & 16.6 \\
\hline 8 & 4.57 & 36 & 0.2 & 2 & 0.375 & 0.3 & 25 & 16.3 \\
\hline 9 & 3.05 & 10 & 0.1 & 1 & 0.25 & 0.3 & 21 & 18.3 \\
\hline 10 & 3.05 & 36 & 0.1 & 1 & 0.25 & 0.3 & 24 & 16.0 \\
\hline 11 & 3.05 & 10 & 0.3 & 1 & 0.25 & 0.3 & 21 & 18.3 \\
\hline 12 & 3.05 & 36 & 0.3 & 1 & 0.25 & 0.3 & 24 & 16.0 \\
\hline 13 & 3.05 & 10 & 0.1 & 1 & 0.5 & 0.3 & 21 & 18.3 \\
\hline 14 & 3.05 & 36 & 0.1 & 1 & 0.5 & 0.3 & 24 & 16.0 \\
\hline 15 & 3.05 & 10 & 0.3 & 1 & 0.5 & 0.3 & 21 & 18.3 \\
\hline 16 & 3.05 & 36 & 0.3 & 1 & 0.5 & 0.3 & 24 & 16.0 \\
\hline 17 & 3.05 & 23 & 0.1 & 0 & 0.375 & 0.2 & 17 & 15.6 \\
\hline 18 & 3.05 & 23 & 0.3 & 0 & 0.375 & 0.2 & 18 & 15.6 \\
\hline 19 & 3.05 & 23 & 0.1 & 2 & 0.375 & 0.2 & 26 & 16.9 \\
\hline 20 & 3.05 & 23 & 0.3 & 2 & 0.375 & 0.2 & 25 & 17.0 \\
\hline 21 & 3.05 & 23 & 0.1 & 0 & 0.375 & 0.4 & 18 & 15.6 \\
\hline 22 & 3.05 & 23 & 0.3 & 0 & 0.375 & 0.4 & 18 & 15.6 \\
\hline 23 & 3.05 & 23 & 0.1 & 2 & 0.375 & 0.4 & 26 & 16.9 \\
\hline 24 & 3.05 & 23 & 0.3 & 2 & 0.375 & 0.4 & 27 & 16.9 \\
\hline 25 & 1.52 & 23 & 0.2 & 0 & 0.25 & 0.3 & 20 & 15.7 \\
\hline 26 & 4.57 & 23 & 0.2 & 0 & 0.25 & 0.3 & 17 & 15.6 \\
\hline 27 & 1.52 & 23 & 0.2 & 2 & 0.25 & 0.3 & 29 & 17.3 \\
\hline 28 & 4.57 & 23 & 0.2 & 2 & 0.25 & 0.3 & 24 & 16.8 \\
\hline 29 & 1.52 & 23 & 0.2 & 0 & 0.5 & 0.3 & 20 & 15.7 \\
\hline 30 & 4.57 & 23 & 0.2 & 0 & 0.5 & 0.3 & 17 & 15.6 \\
\hline 31 & 1.52 & 23 & 0.2 & 2 & 0.5 & 0.3 & 29 & 17.3 \\
\hline 32 & 4.57 & 23 & 0.2 & 2 & 0.5 & 0.3 & 24 & 16.8 \\
\hline 33 & 3.05 & 10 & 0.2 & 1 & 0.25 & 0.2 & 21 & 18.2 \\
\hline 34 & 3.05 & 36 & 0.2 & 1 & 0.25 & 0.2 & 24 & 16.0 \\
\hline 35 & 3.05 & 10 & 0.2 & 1 & 0.5 & 0.2 & 21 & 18.2 \\
\hline 36 & 3.05 & 36 & 0.2 & 1 & 0.5 & 0.2 & 24 & 16.0 \\
\hline 37 & 3.05 & 10 & 0.2 & 1 & 0.25 & 0.4 & 21 & 18.3 \\
\hline 38 & 3.05 & 36 & 0.2 & 1 & 0.25 & 0.4 & 25 & 16.0 \\
\hline 39 & 3.05 & 10 & 0.2 & 1 & 0.5 & 0.4 & 21 & 18.4 \\
\hline 40 & 3.05 & 36 & 0.2 & 1 & 0.5 & 0.4 & 25 & 16.0 \\
\hline 41 & 1.52 & 23 & 0.1 & 1 & 0.375 & 0.2 & 27 & 16.6 \\
\hline 42 & 4.57 & 23 & 0.1 & 1 & 0.375 & 0.2 & 21 & 16.3 \\
\hline 43 & 1.52 & 23 & 0.3 & 1 & 0.375 & 0.2 & 27 & 16.6 \\
\hline 44 & 4.57 & 23 & 0.3 & 1 & 0.375 & 0.2 & 22 & 16.3 \\
\hline 45 & 1.52 & 23 & 0.1 & 1 & 0.375 & 0.4 & 27 & 16.6 \\
\hline 46 & 4.57 & 23 & 0.1 & 1 & 0.375 & 0.4 & 22 & 16.2 \\
\hline 47 & 1.52 & 23 & 0.3 & 1 & 0.375 & 0.4 & 27 & 16.7 \\
\hline 48 & 4.57 & 23 & 0.3 & 1 & 0.375 & 0.4 & 22 & 16.3 \\
\hline 49 & 3.05 & 23 & 0.2 & 1 & 0.375 & 0.3 & 24 & 16.4 \\
\hline
\end{tabular}




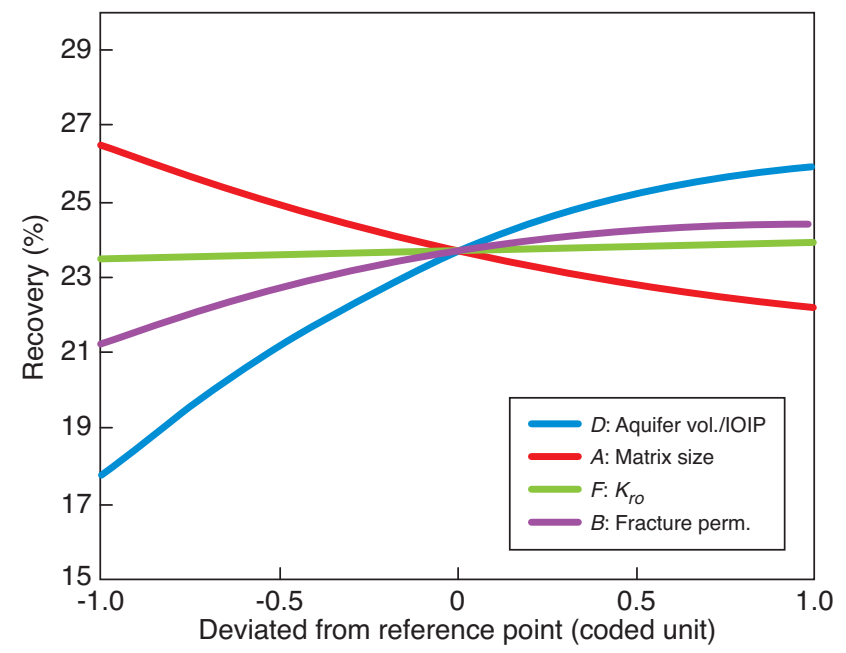

Figure 6

Perturbation plot describing the main influential parameters on recovery.

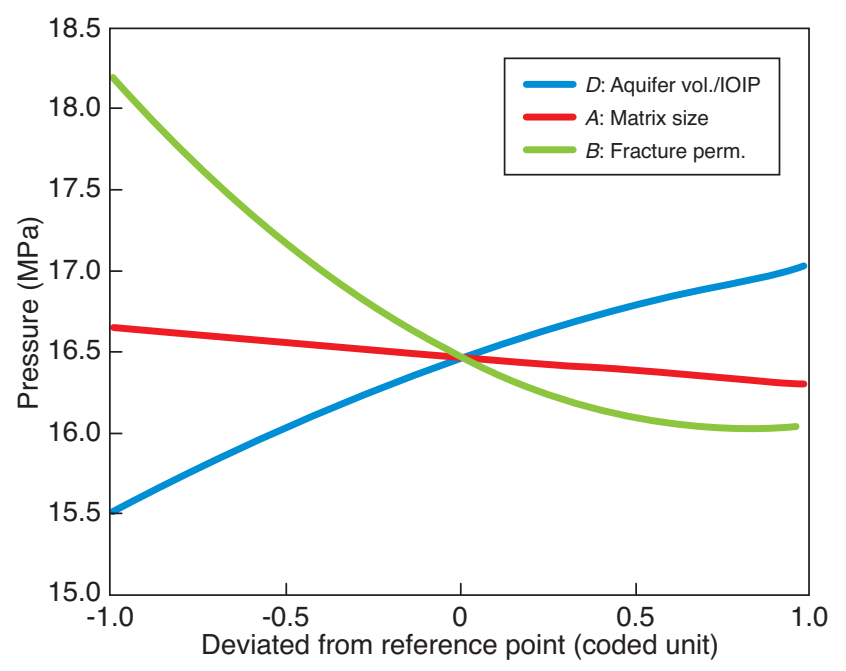

Figure 7

Perturbation plot describing the main influential parameters on recovery.
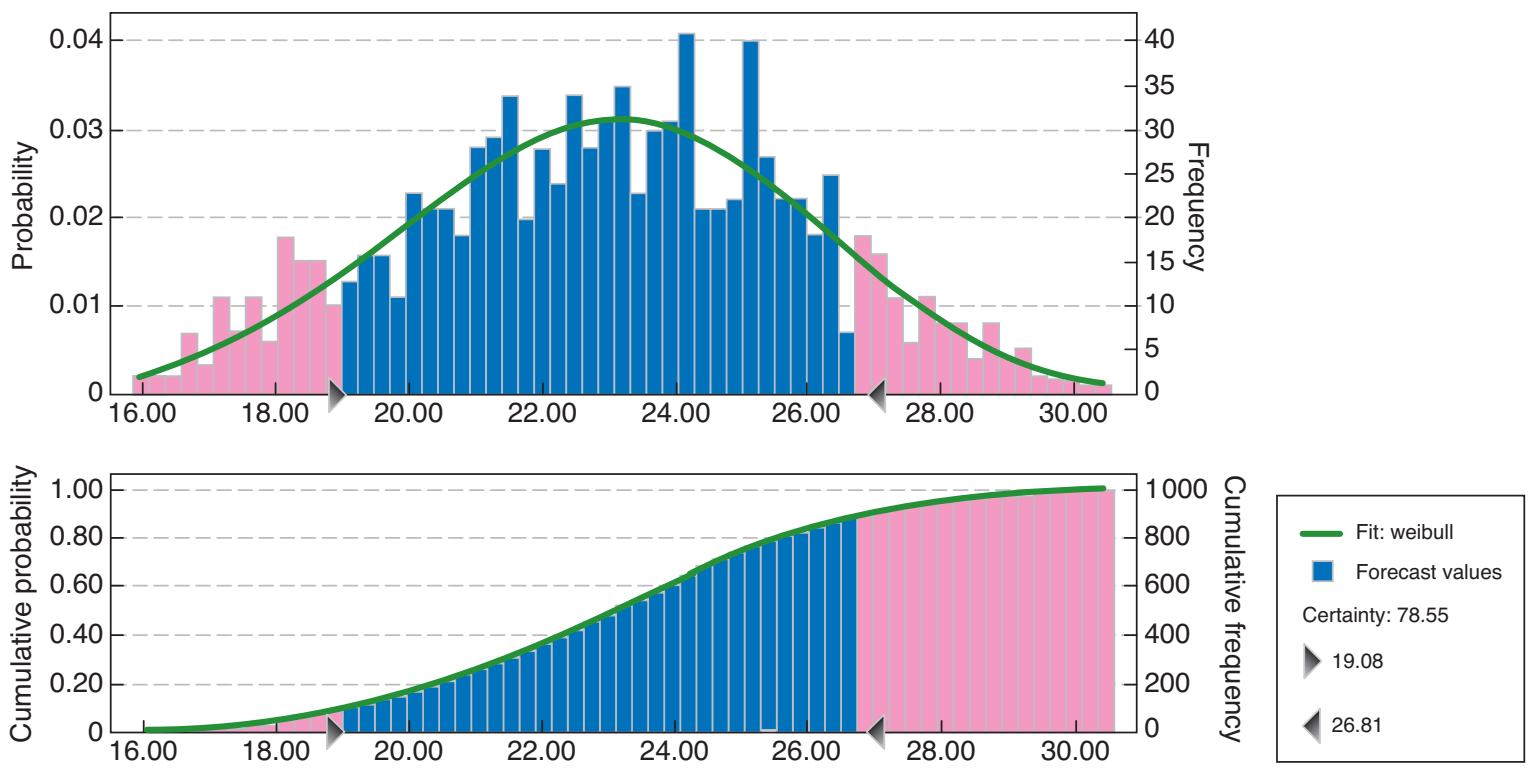

Figure 8

Probability distribution for the recovery factor after 30 years.

as in DOE (low and high levels). Software uses values from their identified intervals in 1000 trials to produce probability distribution for "\% Recovery" which has been defined with the equation derived from DOE (Fig. 7).

After fitting a probability curve to the results, it is possible to find different parameters of probability distribution such as mean, median, 10th percentile and 90th, etc. (Fig. 8).
Sensitivity chart shown in Figure 9 illustrates importance of each factor's effect on response in comparison with the others. For example, in this range of investigation, aquifer size is the most influential parameter, and matrix block size and fracture permeability are the two next important factors. The main concept of this chart is similar to what is shown in Figure 6, as a perturbation graph. 
Effect (\%)

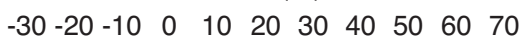

Aquifer vol./IOIP

Matrix size

Fracture permeability

Oil relative permeability

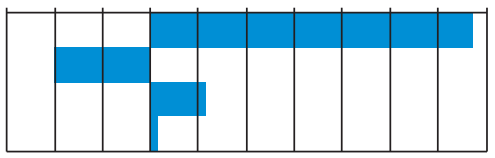

Figure 9

Sensitivity chart for recovery.

From reservoir engineering point of view, Figure 9 mentions that for a reservoir with larger aquifer volume, rate of pressure drop would be lower (as shown in Fig. 7), this lets the wells to keep higher pressure for a longer period of time. Therefore, cumulative oil production will increase at the end of 30 years. In addition, for a reservoir with smaller fractured density, which tends to lower fracture permeability, effective permeability of the reservoir decreases and ability of the reservoir for conduction of oil to the well decreases consequently.

Table 4 shows that distribution shown in Figure 8 mean and median is equal to 22.95 , and mod is 23.01 , which agrees with previous studies on this field.

TABLE 4

Distribution function of recovery

\begin{tabular}{l|c}
\hline Statistics & Values \\
\hline Trials & 1000 \\
\hline Mean & 22.95 \\
\hline Median & 22.96 \\
\hline Mode & 23.01 \\
\hline Standard deviation & 2.96 \\
\hline Variance & 8.79 \\
\hline Skewness & -0.027 \\
\hline Kurtosis & 2.48 \\
\hline Coeff. of variability & 0.129 \\
\hline Minimum & 15.88 \\
\hline Maximum & 30.55 \\
\hline Range width & 14.67 \\
\hline Mean std. error & 0.09 \\
\hline
\end{tabular}

Furthermore, by analyzing the cumulative probability, it could be shown that 10th percentile is 18.9 and 90 th is 26.96 . This is a quit large range of uncertainty from reservoir engineering point of view, because IOIP of the reservoir is about 1 billion barrels of oil and $8 \%$ recovery means 80 million barrels of oil. Therefore, it is necessary to decrease the levels of uncertainty within the reservoir model using the advantages of high technology. For example, it is important to make sure about the aquifer strength and volume or fracture network properties by using different kinds of logs or drilling more observation wells.

Results for pressure variation prediction are shown in Table 5.

TABLE 5

Distribution function of pressure

\begin{tabular}{l|c}
\hline Statistics & Forecast values \\
\hline Trials & 2000 \\
\hline Mean & 16.89 \\
\hline Median & 16.68 \\
\hline Mode & 16.47 \\
\hline Standard deviation & 0.81 \\
\hline Variance & 0.66 \\
\hline Skewness & 0.7347 \\
\hline Kurtosis & 2.84 \\
\hline Coeff. of variability & 0.0481 \\
\hline Minimum & 15.56 \\
\hline Maximum & 19.37 \\
\hline Range width & 3.81 \\
\hline Mean std. error & 0.02 \\
\hline
\end{tabular}

Probability distribution of ultimate reservoir pressure has been shown in Figure 10. Table 5 illustrates that mean of this distribution is equal to 16.89 , median 16.68 , and mod 16.47 .

Cumulative probability shows that P10 is 15.96 and P90 is 18.11 .

Sensitivity chart (Fig. 11) identifies that which parameter has the biggest effect on pressure, and what is the rank of each parameter regarding to their normalized effect. It could be shown that fracture permeability has the largest negative effect on pressure drop; it means rate of pressure drop would be more in a reservoir with higher fracture permeability, which is a reasonable statement in reservoir engineering. Then, aquifer volume as a supporter has a positive effect on pressure. This implies that, when strong aquifer volume connected to the reservoir, reservoir pressure decreases very gently.

\section{CONCLUSION}

This paper demonstrates how Experimental Design could be used in forecasting the probable performance of oil reservoir 


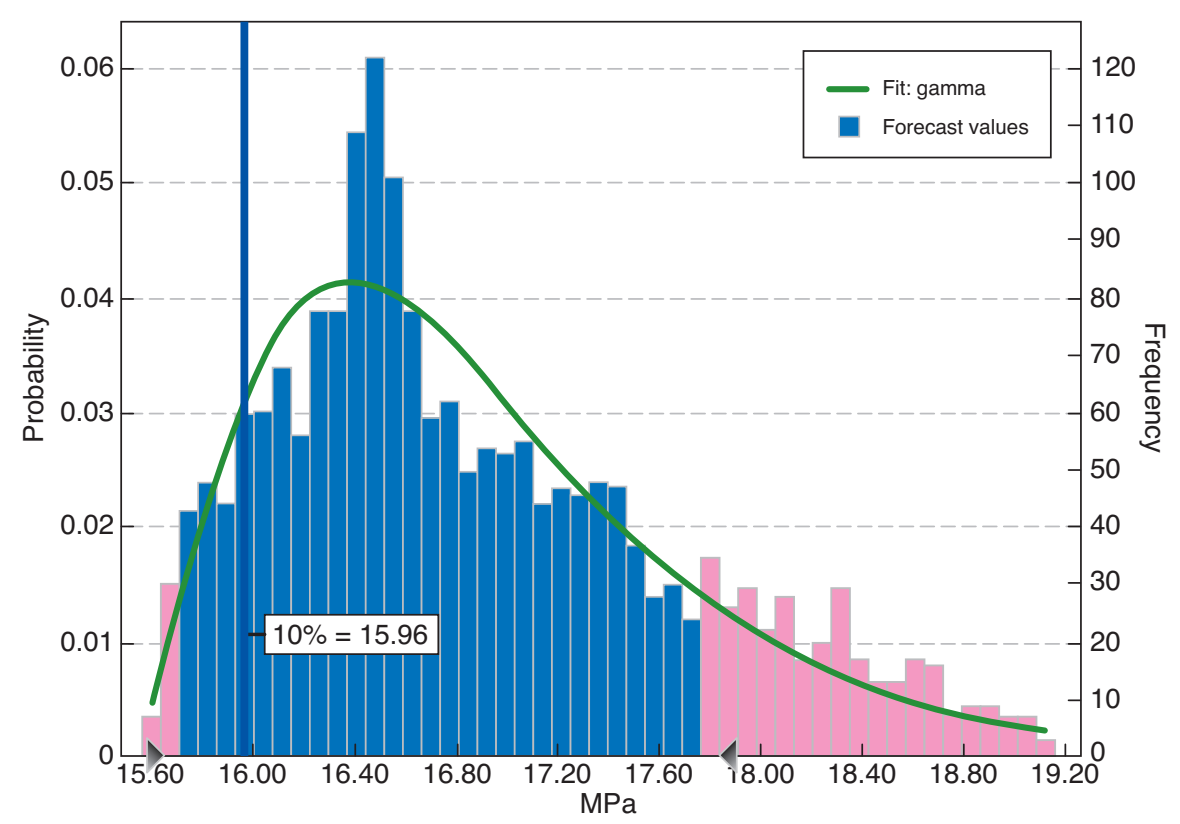

Figure 10

Probability distribution for reservoir pressure after 30 years.

Effect (\%)

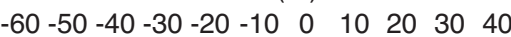

$D$ : Aquifer vol/IOIP

A: Matrix size

$B$ : Fracture permeability

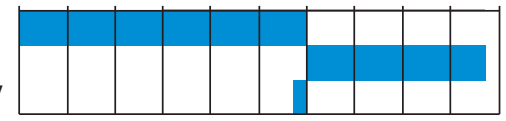

Figure 11

Sensitivity chart for pressure.

during its lifetime. Box-Behnken method was used to find the most influential parameters on pressure and recovery, as well as finding a proxy equation to model the responses. DOE identified that for natural depletion in a fractured reservoir like the one studied in this paper, the most significant parameters were: ratio of aquifer volume to the IOIP, matrix size, and fracture permeability. Furthermore, oil recovery was a week function of oil relative permeability while the reservoir was fractured.

The proxy model allowed the study of the full distribution of oil recovery and reservoir pressure rather than just its expected value, by using the Monte-Carlo analysis. Although, the results show the most probable recovery for this model is about 23\% (which is in agreement with previous studies on this field), there is a large difference between 10th percentile probability (18.9) and 90th (26.96). In terms of reservoir engineering, $8 \%$ recovery factor, based on IOIP of this field, means 82 million barrels of oil. Therefore, it is necessary to reduce the uncertainty of the model parameters by extended field analysis technologies.

\section{ACKNOWLEDGMENTS}

The authors would like to thank F. Kamali and A. Vahidi from National Iranian Oil Company (NIOC) for their contribution in developing the reservoir model. In addition, thanks go to ICOFC's experts and also Research and Technology Directorate (R\&T) for their help and support.

\section{REFERENCES}

1 Zabalza-Mezghani I., Manceau E., Feraille M., Jourdan A. (2004) Uncertainty management: From geological scenarios to production scheme optimization, J. Petrol. Sci.Eng. 44, 1-2, 11-25.

2 Zhang J., Delshad M., Sepehrnoori K. (2007) Development of a framework for optimization of reservoir simulation studies, J.Petrol.Sci. Eng. 59, 1-2, 135-146.

3 Peng C.Y., Gupta R. (2004) Experimental design and analysis methods in multiple deterministic modeling for quantifying hydrocarbon in-place probability distribution curve, SPE Asia Pacific Conference on Integrated Modeling for Asset Management, Kuala Lumpur, Malaysia, 29-30 March.

4 Esmaiel T.E.H., Fallah S., Kruijsdijk C.P.J.W. (2005) Reservoir screening and sensitivity analysis of waterflooding with smart wells through the application of experimental design, 14th SPE Middle East Oil \& Gas Show and Conference, Bahrain, 12-15 March.

5 Myers R.H., Montgomery D.C. (1995) Response Surface Methodology - Process and Product Optimization Using Designed Experiments, John Wiley \& Sons, New York.

6 Narayanan K., White C.D., Lake L.W. (1999) Response surface methods for upscaling heterogeneous geologic models, SPE Reservoir Simulation Symposium, Houston, Texas, 14-17 February. 
7 Chewaroungroaj J., Varela O.J., Lake L.W. (2000) An evaluation of procedures to estimate uncertainty in hydrocarbon recovery prediction, SPE Asia Pacific Conference on Integrated Modelling for Assest Management, Yokohama, Japan, 25-26 April.

8 White C.D., Willis B.J., Narayanan K., Dutton S.P. (2001) Identifying and estimating significant geologic parameters with experimental design, Soc. Pet. Eng. J. 6, 3, 311-324.

9 Risso F.V.A., Risso V.F., Schiozer D.J. (2007) Risk Assessment of Oil Fields Using Proxy Models: a case study, 8th Canadian International Petroleum Conference (58th Annual Technical Meeting), Calgary, Canada, 12-14 June.
10 Rai K., Johns R.T., Delshad M. (2009) Oil-Recovery Predictions for Surfactant Polymer Flooding, SPE Annual Technical Conference and Exhibition, New Orleans, Louisiana, 4-7 October.

11 Damsleth E., Hage A., Volden R. (1992) Maximum Information at Minimum Cost: A North Sea Field Development Study with an Experimental Design, J. Petrol. Technol. 44, 12, 1350-1356.

12 Dejean J.P., Blanc G. (1999) Managing Uncertainties on Production Prediction Using Integrated Statistical Methods, SPE Annual Technical Conference and Exhibition Proceedings, Houston, Texas, 3-6 October.

Final manuscript received in May 2011 Published online in May 2012

Permission to make digital or hard copies of part or all of this work for personal or classroom use is granted without fee provided that copies are not made or distributed for profit or commercial advantage and that copies bear this notice and the full citation on the first page. Copyrights for components of this work owned by others than IFP Energies nouvelles must be honored. Abstracting with credit is permitted. To copy otherwise, to republish, to post on servers, or to redistribute to lists, requires prior specific permission and/or a fee: Request permission from Information Mission, IFP Energies nouvelles, fax.+33147527096, or revueogst@ifpen.fr. 